\title{
ANALISIS HEGEMONI DALAM DWILOGI NOVEL NEGERI PARA BEDEBAH KARYA TERE LIYE (PERSPEKTIF ANTONIO GRAMSCI)
}

\author{
Ida Nuswantaria \\ Madrasah Aliyah Negeri Babat Kabupaten Lamongan \\ Telp.(0322) 451471 \\ Hp. 081217767605 \\ Pos-elnuswantaria_ida@yahoo.co.id
}

\begin{abstract}
This research aimed ad describing (1) the types of hegemony that included physical and psychological hegemony. (2) the techniques of hegemony, including oppressive, intellectual, and moral hegemony. (3) thescopeof hegemony, including micro and macro. Thisresearch used Gramsci Antonio Theory.This research uses qualitative method. The sources of data are novels by TereLiye entitled Negeri Para Bedebah and Negeri Diujung Tanduk novels. Data collection used documentation, reading, and taking note. Data were analyzed descriptively. Validity of data was tested by using close observation and triangulation.The results of the research are as follows: (1) the types of hegemony in the two novels are physical hegemony and psychology hegemony. (a) physical hegemony includes the hegemony of the police to thomas, Wusdi to Thomas, SAR the Hongkong Antiteror Force to Kadek, SAR to Opa, Thomas, and Maryam. (b)psychology hegemony includes the General Commisioner police officer to Thomas, Opa to Thomas, Julia to Thomas, Thomas to Maggie, Thomas to Julia and Ram to Opa. (2) hegemony techniques used are oppressive,intellectual, and morality hegemony. Oppressive method are being practiced by Mr. shinpei at Thomas' family using his minions; wusdi, Tunga and Ram. Intellectual and morality hegemony are divided into three: (1) traditional intellectual included (a) Thomas to Maggie and (b) JD to Thomas, (2) organic intellectual included (a) Maryam to Thomas, (b) Detective Liu to Thomas, and (3) Thomas to JD, and (3) consensus includes (a) Thomas to Lee, (b) Maryam to Thomas , (c) Thomas to jailer officer, and (d) Thomas to client. (3) Hegemony scope includes (a) micro hegemony includes Liem to Edward and Mama to Thomas, and (b) macro hegemony includes wusdi to Thomas, Ram to Tunga and wusdi and JD to Thomas. Hegemonies in thi scope are also done in the economic and political perspectives.
\end{abstract}

Keywords: Antonio Gramsci hegemony, types of hegemony, hegemony techniques, and the scope of hegemony

Abstrak: Penelitian ini bertujuan untuk mendeskripsikan (1) jenis hegemoni yang mencakup hegemoni fisik dan psikis, (2) teknik hegemoni yang mencakup penindasan, intelektual, dan moral, (3) ruang lingkup hegemoni yang mencangkup mikro dan makro. Penelitian ini menggunakan teori hegemoni Antonio Gramsci. Penelitian ini menggunakan metode kualitatif. Sumber data dalam penelitian ini adalah novel Negeri Para Bedebah dan Negeri Di Ujung Tanduk Karya Tere Liye. Pengumpulan data dilakukan dengan teknik dokumentasi, membaca, dan mencatat. Teknik analisis data yang digunakan adalah teknik analisis deskriptif. Untuk menguji keabsahan data, teknik yang digunakan adalah teknik ketekunan pengamatan dan triangulasi. Hasil penelitian 
ini sebagai berikut (1) jenis analisis hegemoni dalam dwilogi novel Negeri Para Bedebah karya Tere Liye mencangkup (a) hegemonifisik yang meliputi polisi kepada Thomas, Wusdi kepada Thomas, pasukan Antiteror Hongkong SAR kepada Kadek, dan pasukan Antiteror Hongkong SAR kepada Opa, Thomas, dan Maryam, sedangkan (b) hegemoni psikis yang meliputi tokoh bintang tiga polisi kepada Thomas, Opa kepada Thomas, Julia kepada Thomas, Thomas kepada Maggie, Thomas kepada Julia, dan Ram kepada Opa. (2) teknik analisis hegemoni dilakukan secara penindasan intelektual dan moral. Teknik penindasan dilakukan Tuan Shinpei kepada keluarga Thomas melalui kaki tangannya, Wusdi, Tunga dan Ram, sedangkan teknik hegemoni secara intelektual terbagi menjadi 3 yaitu (1) intelektual tradisional mencangkup (a) Thomas kepada Maggie, dan (b) JD Detektif Liu kepada Thomas, (2) intelektual organic mencangkup (a) Maryam kepada Thomas, (b) detektif Liu kepada Thomas, (c) Thomas kepada JD dan (3) konsensus mencangkup (a) Thomas kepada Lee, (b) Maryam kepada Thomas, (c) Thomas kepada komandan sipir, dan (d) Thomas kepada nasabah. (3) ruang lingkup hegemoni mencakup (1) mikro yang meliputi (a) om Liem kepada papa Edward dan (b) mama kepada Thomas, dan (2) makro yang meliputi (a) Wusdi kepada Thomas, (b) Ram kepada Tunga dan Wusdi, dan (c) JD kepada Thomas. Di samping itu hegemoni dilakukan dalam ruang lingkup tersebut mencakup secara ekonomi politik.

Kata Kunci: hegemoni Antonio Gramsci, jenis hegemoni, teknikhegemoni, dan ruang lingkup hegemoni

\section{PENDAHULUAN}

Novel merupakan salah satu bentuk karya sastra yang memunculkan nilainilai positif bagi pembaca sehingga mereka peka terhadap masalah-masalah yang berkaitan dengan kehidupan sosial dan mendorong untuk berperilaku yang baik. Novel dianggap sebagai refleksi zaman yang dapat mengungkapkan aspek sosial, budaya, politik, dan ekonomi. Novel juga merupakan ungkapan fenomena sosial dalam aspek-aspek kehidupan yang dapat digunakan sebagai sarana mengenal manuisa dan zamannya.

Seiring berkembangnya zaman, novel khususnya di Indonesiamengalami perkembangan yang sangat pesat. Hal tersebut terlihat dari banyaknya penulis baru dengan menuliskan karya sastra yang bersifat populer dan digemari kaum remaja. Penulis-penulis novel piawai menuangkan berbagai konflik ke dalam novel yang ditulisnya. Jadi, tidak tertutup kemungkinan dalam novel yang berkembang di masa kini adalah cerita dwilogi novel yang berjudul Novel Negeri Para Bedebah dan Negeri Di Ujung tanduk. Dwilogi novel ini berisi tentangpenghianatan, balas dendam, cinta, persahabatan, kehormatan, kepedulian, penindasan, kekuasaan dan prinsip hidup pada tiap tokohnya.

Pada karya tersebut Tere Liye menuangkan ide yang bernuansa sosial, politik, dan ekonomi. Sesuai yang digambarkan dalam prolog dibagian cover belakangnya: negeri para bedebah, musang berbulu domba berkeliaran di halaman rumah. Tetapi setidaknyakawan, di Negeri Para Bedebah, petarung sejati tidak akan pernah berkhianat pada novel Negeri Di Ujung Tanduk,kehidupan semakin rusak, bukan karena orang jahat semakin banyak, namun karena banyak orang yang memilih tidak peduli lagi. Membaca novelNegeri Para Bedebah dan Negeri Di Ujung tanduk ini seperti menggambarkan kondisi dari aspek perpolitikan dan perekonomian dalam suatu negara. 
Dwilogi novel tersebut terdapat hegemoni yang dilakukan tokoh yang satu dengan tokoh lainnya, antar individu dengan kelompok, dan kelompok dengan kelompok lain.

Hegemoni yang dilakukan tokoh dalam Novel Negeri Para Bedebah dan Negeri Di Ujung Tanduk karya Tere Liyeini terjadi melalui intelektual dan moral. Dari intelektual dan moral muncullah kesepakatan antara seorang tokoh dengan tokoh lainnya sehingga melibatkan kelompok sosial yang satu dengan kelompok sosial lainnya. Hal tersebut sesuai yang diungkapkan Gramsci bahwa kelas sosial memperoleh keunggulan melalui dua cara yaitu melalui cara dominasi dan kedua melalui intelektual dan moral. Cara yang terakhir (melalui intelektual dan moral) inilah yang kemudian disebut sebagai hegemoni (Patria dan Arief, 2009:117-119).

Kekuasaan yang ditampilkan tokoh yang meraih dengan kepemimpinan secara penindasan tidak akan mampu terus bertahan karena kekuasaannya tersebut begitu buruk dan merugikan pihak lainya. Seiring berjalannya waktu pihak keluarga tokoh dan rekan kerja menemukan kesadaran akan hak-haknya. Perubahan kekuasaan yang dicapai dengan upaya meraih kesepakatan antara tokoh dan keluarga serta rekan kerjanya melalui praktik hegemoni, yakni kepemimpinan secara intelektual dan moral.

Dwilogi novel tersebut dikaji dengan alasan, pertama novel yang berjudul Negeri Para Bedebah dan Negeri Di Ujung Tanduk, politik terdapat aspek sosial, dan ekonomi. Kedua novel karya Tere Liye ini penuh intrik dan komplikasi pada tokohnya seperti adanya masalah yang terjadi diantara para tokoh, baik tokoh dengan tokoh, tokoh dengan tempat, maupun tokoh dengan suasana yang terdapat dalam cerita rekaan.
Ketiga, dwilogi novel tersebut masih di anggap kurang menarik minat membaca di kalangan remaja di sebabkan kalangan remaja lebih suka terhadap karya-karya yang berisi tentang hal-hal yang dapat mudah dipahami tanpa membutuhkan pemikiran yang lebih dalam. Keempat, dwilogi novel ini dapat membuka pandangan masyarakat mengenai sosial, politik dan perekonomian di Indoneisa. Dalam hal ini kejadian cerita novel sangat relevan dengan fenomena yang terjadi di Negara Indonesia beberapa tahun belakang ini. Kelima, terdapat hegemoni melalui kepemimpinan intelektual dan moral serta konsensus pada tokoh cerita dalam dwilogi novel Tere Liye. Keenam, diharapkan dwilogi novel ini dapat mendidik masyarakat Indonesia untuk lebih arif dan bijaksana dalam menghadapi hidup berbangsa dan bernegara.

Berdasarkan alasan tersebut peneliti bermaksud mengkaji novel Tere Liye menggunakan kajian hegemoni Antonio Gramsci. Alasannya, karena tokoh dalam novel menggunakan hegemoni melalui kepemimpinan dan moral serta tidak lepas dari hubungan kesepakatan antartokoh. Selain itu, teori Antonio Gramsci di anggap lebih tepat untuk mengkaji novel berjudul Negeri para bedebahdan Negeri Di Ujung Tanduk karya Tere Liye dengan berbagai hal mengenai jenis, teknik dan ruang lingkup hegemoni.

Berdasarkan paparan di atas, perlu adanya penelitian yang bertujuan untuk Tujuan umum penelitian ini adalah menemukan Analisis hegemoni dalam dwilogi novel Negeri Para Bedebah karya Tere Liye (Perspektif Antonio Gramsci). Secara khusus, penelitian ini dimaksud untuk :(1) mendeskripsikan Jenis hegemoni dalam dwilogi novel Negeri Para Bedebah karya Tere Liye (Perspektif Antonio Gramsci), 
mendeskripsikan Teknik hegemoni dalam dwilogi novel Negeri Para Bedebah karya Tere Liye (Perspektif Antonio Gramsci), (3) mendiskripsikan Ruang lingkup hegemoni dalam dwilogi novel Negeri Para Bedebah karya Tere Liye (Perspektif Antonio Gramsci).Teori Hegemoni. Hegemoni adalah sebuah kekuasaan yang didapat melalui mekanisme konsensus (consensus) daripada melalui penindasan terhadap kelas sosial lain. Ada berbagai cara yang digunakan, misalnya melalui masyarakat yang menentukan secara langsung atau tidak langsung struktur-struktur koginitif. Itulah sebabnya hegemoni pada hakikatnya adalah upaya untuk menggiring seseorang agar menilai dan memandang problematika sosial dalam kerangka yang ditentukan. Dalam konteks tersebut, Gramsci lebih menekankan pada aspek kultural (ideologis). Melalui produk-produknya, hegemoni menjadi satu-satunya penentu dari sesuatu yang dipandang baik benar secara moral maupun intelektual. Hegemoni kultural tidak hanya terjadi dalam relasi antar negara tetapi dapat juga terjadi dalam hubungan antar berbagai kelas sosial yang ada dalam suatu negara.

Istilah hegemoni pertama kali dipakai oleh Plekanov dan pengikut Marxis Rusia lainnya pada tahun 1880-an untuk menunjukan perlunya kelas pekerja untuk membangunaliansi dengan petani bertujuan meruntuhkan gerakan rarisme ( Simon, 2004: 20). Istilah "hegemoni"berkembang menjadi sebuah konsep melalui beberapa tokoh-tokoh hegemoni yang terus menerus mengalami perbaikan. Tokoh-tokoh hegemoni mengalami pebaikan. Tokoh-tokoh hegemoni tersebut antara lain Karl Marx, Lenin dan Antonio Gramsci. Pandangan Marx tentang "hegemoni"borjuis dalam masyarakat sipil seperti yang di ungkapkan oleh Max dan Engels dalam The Germany Ideology(Patria dan Arief, 2009:13).

Ada tiga argumen teoretis dari Marx, pertama Marx memandang kondisi material dari masyarakat sebagai basis dari struktur sosial dan kesadaan manusia. Bentuk Negara pun muncul dari hubungan-hubungan podksi dan bukannya berasal dari perkembangan umum pemikiran manusia atau keinginan manuisa untuk berkolektif. Marx memetakan negara dalam konteks historis dan menariknya menjadi sebuah konsepsi materialis tentang sejarah. Artinya bukannya Negara yang membentukmasyarakat tapi masyarakat yang membentuk negara. Masyarakat, pada gilirannya, dibentuk oleh cara produksi yang didalamnya. Dengan demikian, bidang ekonomi merupakan basis (basic structure), sedangkan kedua, kehidupan masyarakat lainnya, institusiinstitusi sosial, terutama Negara bentukbentuk kesadaran sosial merupakan bangunan atas (super structure).

\section{METODE PENELITIAN}

Penelitian ini dirancang dengan menggunakan pendekatan penelitian kualitatif. Penelitian kualitatif ini merupakan prosedur penelitian yang menghasilkan data deskriptif berupa katakata tertulis pada teks karya sastra yaitu novel. Penelitian kualitatif ini dipilih karena bertujuan mendiskripsikan jenis,teknik,dan ruang lingkup hegemoni dalam novel Negeri para bedebah dan negeri di ujung tanduk karya Tere Liye.

Data merupakan suatu hal pokok dalam penelitian karena tanpa data seorang peneliti tidak mungkin dapat menganalisis data yang diinginkan. Data penelitian ini berupa teks dalam sumber data yang sesuai dengan rumusan masalah yang diperoleh dari novel negeri para bedebah dan negeri di ujung 
tandukkarya Tere Liye. Data penelitian berupa kata, frase, kalimat, paragraph, dan wacana dalam sumber data

Sumber data dalam penelitian ini adalah novel berjudul negeri para bedebah dan negeri di ujung tanduk karya Tere Liye. Novel negeri para bedebah ini diterbitkan oleh penerbit Gramedia pustaka Utama, tahun terbit 2012 dan terdiri atas 440 halaman sedangkan novel Negeri Di Ujung Tanduk pada tahun 2013 dan terdiri 360 halaman. Peneliti memilih novel negeri bedebah dan negeri di ujung tanduk karya Tere Liye disebabkan novel tersebut merupakan terbitan 2012 dan 2013 yang menyangkut persoalan kekinian. Selain itu, dwilogi novel tersebutmenjadi populer dikalangan orang dewasa. Novel ini menarik, menceritakan carut marutnya negeri kita dalam hal perekonomian yang sebenarnyadikuasai oleh mereka yang berduit dan bagaimana uang begitu berkuasa sehingga hukum dapat dibeli.

Data penelitian ini berupa kata,kalimat,dan wacana berbentuk penggalan cuplikan, alenia, dialog-dialog, pelukisan tokoh, dan tindakan tokoh yang mengandung informasi-informasi yang menunjukan jenis hegemoni, teknik hegemoni, dan ruang lingkup hegemoni dalam novel Negeri para Bedebah dan Negeri di ujung Tanduk karya Tere Liye.

Pengumpulan data dalam penelitian ini dilakukan dengan teknik dokumentasi, membaca dan mencatat teknik dokumentasi dengan memanfaatkan sumber dokumen, berupa novel negeri para bedebah dan negeri di ujung tanduk karya Tere Liye. Teknik dokumentasi dalam penelitian ini dilakukan dengan mengeksplorasi atau menyelidik sumber informasi pendukung tertulis yaitu berupa data-data yang relevisinya dengan fokus penelitian.
Teknik membaca digunakan untuk menyerap dan menginterpretasikan data tertulis dengan membaca dwilogi novel karya Tere Liye. Teknik mencatat yang digunakan untuk pencatatan hasil pengamatan dari dwilogi novel karya Tere Liye sesuai dengan fokus penelitian yaitu jenis, teknik dan ruanag lingkup hegemoni.

Dari hasil pengamatan tersebut dapat dimasukkan pada korpus data sehingga dapat mempermudah dalam penganalisian data. Teknik membaca dapat dilakukan dengan membaca dengan cermat setiap novel dari awal sampai akhir. Membaca ulang novel yang pernah dibaca untuk menguatkan data tertulis yang akan dikumpulkan, membandingkan data satu dengan yang lainnya dalam setiap novel untuk memilih data yang tepat.

\section{HASIL PENELITIAN DAN PEMBAHASAN}

Jenis Hegemoni Gramsci,Gramsci (Simon, 2004 : 19) membagi hegemoni menjadi dua jenis, yakni kekerasan hegemoni Fisik dan Psikis.

\section{Hegemoni Fisik}

Menurut Gramsci, dominasi yang dilakukan dengan kekerasan justru akan menimbulkan resistensi dari mereka yang didominasi. Meskipun Negara mempunyai hak untuk menggunakan kekerasan, namun negara juga harus melakukan hegemoni melalui kepemimpinan moral dan intelektual.

Polisi tersebut membawa senapan yang diarahkan ke tubuh Thomas dan sengaja memborgolnya agar tidak melawan. Dengan begitu polisi menyuruh Thomas agar bergegas berjalan menuju mobil taksis. Seperti terlihat pada kutipan berikut.

"Bergegas, atau kutembak kakimu!"
salah satu dari polisi membentak.
Aku menghembuskan napas,
melangkah lebih cepat. Mereka


menggiringku menuju salah satu mobil taktis yang terparkir persis di depan lobi keberangkatan, membuat kemacetan.

"Naik!" popor senjata kembali menyodok perutku.

Aku mengeluh. Tidak bisakah meraka berhitung dengan situasi? Dengan balasan polisi, aku pasti menuruti semua perintah, tidak perlu dipaksa dengan kekerasan.

Tapi sebaliknya, petugas polisi malah mendorongku kasar. Untuk kedua kalinya aku tersungkur (Npb, 2012:180).

Berdasarkan kutipan tersebut terlihat kasus yang menyeret Thomas dalam kriminal setelah membawa kabur Om Liem pada malam hari itu.saat berada di Jakarta, Thomas dikepung oleh beberapa polisi lengkap dan memborgol tangannya. Dominasi ini membuat Thomas tidak berdaya, tindakan yang dilakukan polisi kepada Thomas tidak mengenal situasi yang begitu ramai tepat di lobi kedatangan bandara di Jakarta.

\section{Hegemoni Psikis}

Jenis hegemoni psikis adalah hegemoni yang dilakukan oleh tokoh yang satu dengan memanfaatkan verbal dan nonverbal untuk menghegemoni tokoh lainnya. Berikut penjabaran dan kutipan yang menunjukkan hegemoni psikis.

Ancaman yang dilontarkan Bintang tiga polisi kepada Thomas ini menunjukkan psikisnya tertekan. Dibuktikan pada kutipan berikut.

"Bagaimana aku bisa menyelamatkan Maggie dari sana? Dengan jumlah polisi lebih dari setengah lusin, jangankan menyelamatkan Maggie, mendekati lantai kantorku saja tidak mudah. Sejak mengebut tadi aku sudah memikirkan scenario, tapi buntu. Tidak ada cela. Jangankan Maggie yang sendirian dan dijaga setengah lusin pasukan, kami berempat_aku, Julia, Opa, dan Om
Liem-kemarin sore bahkan tidak bisa kabur jika tidak ada bantuan Rudi ((Npb, 2012:300).

Sekalipun tidak hegemoni yang dilakukan Bintang tiga polisi berhasil membuat psikis Thomas bingung dan tertekan.

\section{Teknik Hegemoni Gramsci Intelektual}

Gramsci membedakan kaum intelektual yaitu intektual tradisional dan intelektual organic. Intelektual tradisional adalah para intelektual yang memiliki profesi khusus (seperti para ahli di bidang ilmu pengetahuan, bidang satra dan lain sebagainya) sedangkan yang kedua adalah intelektual organic, yaitu mereka yang mengorganisasi dan memikirkan organisasi tertentu. Oleh karena itu, konteks tersebut dapat menginspirasi atau mendorong dinamika sosial dan mewujutkan bahwa kaum intelektual memiliki peran paling besar di dalam menyebarkan ideology-idiologi perubahan social.

\section{Intelektual Tradisional}

Intelektual tradisional merupakan teknik hegemoni yang dilakukan seorang tokoh kepada tokoh lain tanpa ada penjelasan yang relevan. Seseorang yang terhegemoni akan tetap melakukan apa saja yang sudah diujarkan oleh si penghegemoni.

Hegemoni tradisional terjadi kepada Maggie ketika Thomas menghubunginya pukul dua dini hari. Dalam novel Negeri Para Bedebah diceritakan bahwa Thomas meminta Maggie bergegas berangkat ke kantor malam itu. Thomas tidak memberikan penjelasan yang jelas kepada Maggie hal apa saja yang akan dikerjakan pada pukul dua dini hari, Thomas membutuhkan Maggie disaat sulit yang dihadapinya setelah membawa kabur Om Liem. 
Berikut kutipan yang menunjukkan hegemoni Thomas kepada Maggie.

"Maggie, maaf membangunkanmu malam-malam," aku langsung berseru sambil menekan klakson panjang... "Aku tidak punya waktu untuk menjelaskan, Maggie. Situasi darurat. Aku tahu, tentu saja aku tahu sekarang pukul dua dini hari, dan aku tidak sedang mabuk. Kau segera berkemas, aku butuh kau berada di kantor saat ini. Ada banyak yang harus dikerjakan. Kau dengar aku, Maggie? Segera bergegas, atau promosimu minggu lalu kubatalkan ( $\mathrm{Npb}$, 2012:54).”

Berdasarkan hegemoni tersebut Thomas yang tidak menjelaskan apa yang terjadi sementara waktu dini hari jelas kantor belum di buka. Thomas terlihat serius dengan menyuruh Maggie karena jika tidak mengikuti perintahnya maka promosi yang dijanjikannya akan dibatalkan. Situasi darurat yang dihadapi Thomas ini sudah melibatkan sekretarisnya, Maggie.

\section{Intelektual Organik}

Intelektual organik merupaka salah satu cara untuk memberikan kesadaran dalam menghegemoni seseorang dan memberikan edukasi yang mengarahkan apa saja yang sedang dialami olehindividu, kelompok sosial lainnya yang terdominasi demi tercapainya kepentingan kelompok masyarakat. Dalam novel Negeri Para Bedebah tidak ditemukan teknik hegemoni secara intelektual organik sedangkan pada Negeri Di Ujung Tandukterdapat tokoh yang melakukan hegemoni secara intelektual organik. Berikut penjabaran dan kutipan hegemoni secara Intelektual Organik.

Berikut kutipan yang menunjukkan bahwa Maryam menghormati Thomas dengan cara intelektual organik.
"Gadis itu menggeleng. "Waktuku amat terbatas, aku harus segera kembali ke Jakarta nanti siang. Kami terpaksa mengundurkan jadwal terbit edisi spesial review mingguan kami dua belas jam hanya untuk wawancara ini. Aku hanya butuh waktu Anda sebentar, paling lama satu jam. Tidak lebih (Ndut, 2013:47).

Berdasarkan kutipan tersebut terlihat bahwa Maryam menerangkan bahwa tujuannya untuk mewawancarai Thomas dan dia tidak punya waktu lama karena siang harus kembali ke Jakarta. Pimpinan redaksi Maryam telah mengundur dua.

\section{Konsensus}

Hegemoni didefinisikan sebagai dominasi oleh satu kelompok terhadap kelompok yang lain tanpa ancaman sehingga ide-ide yang didiktekan oleh kelompok dominasi terhadap kelompok yang didominasi atau dikuasai dapat diterima sebagai sesuatu yang wajar. Gramsci (Patria dan Arief, 2009 : 126) lebih mewujudkan suatu hipotesis bahwa terciptanya karena dasar persetujuan. Bagi Gramsci, hegemoni melaluikonsensus muncul melalui komitmen aktif atas kelas sisoal. Untuk itu, Gramsci menyatakan secara tak langsung konsensus sebagai "komitmen aktif" yang didasarkan pada adanya pandangan bahwa posisi tinggi yang ada sah (ligitimate). Konsensus ini secara historis "lahir" disebabkan oleh prestasi yang berkembang dalam dunia produksi (Patria dan Arief, 2009 : 126)

“ ini hidupku, Thomas. Aku jelas menjadi bagian dari empat tersangka yang melarikan diri dari kepolisiaN Hongkong. Jadi aku berhakuntuk memutuskan apa yang harus kulakuan, mencari penjelasan. Kalau kau tidak mau mengajakku, aku akan melakukiannya sendirian. "Tekad Maryam sudah bulat."Baik. kau ikut denganku, Maryam." Maryam tersenyum 
lebar. Wajahnya terlihat bersemangat (Ndut, 2013:145-146).

Pada kutipan tersebut terlihat penghegemonian yang dilakukan Maryam kepada Thomas dengan cara meyakinkan dan memaksa karena dia bertekad jika Thomas tidak mengajaknya maka dia akan melakukannya sendiri.

\section{Ruang Lingkup Hegemoni}

Mengenai ruang lingkup hegemoni, Faruk (2014:132) menyatakan Gramsci bukanlah orang pertama yang mengemukakan konsep hegemoni. Sebelumnya telah ada hegemoni Marx yang lebih menekankan konsep hegemoni pada bidang politik dalam kaitannya dengan pemerintah. Namun bagi Gramsci, konsep hegemoni tidak sebatas dalam bidang politik tetapi lebih kompleks.

\section{Ruang Lingkup Mikro}

Ruang lingkup mikro dalam arti sempit terdapat pada novel Negeri para Bedebah. Ruang lingkup tersebut merupakan hegemoni yang dilakukan oleh tokoh di dalam anggota keluarga seperti Om Liem kepada Papa Edward dan Mama kepada Thomas. Berikut penjabaran hegemoni dalam arti sempit yang dialami oleh tokoh di dalam sebuah keluarga.

Om Liem yang berambisius ingin menjalankan ide barfunya itu daripada menghabiskan hidup dengan berjualan tepung terigu. Berikut kutiupan yang menunjukkan hegemoni OM Liem kepada Papa Edward dalam aspek ekonomi.

"Justru itu poinnya. Ketika orangorang lain sibuk memikirkan bias atau tidak, terbiasa atau tidak, terbiasa atau tidak, terbiasa atau tidak, kita sudah berlari kencang. Aku tidak akan menghabiskan hidup hanya berdagang tepung terigu. Kita tidak akan jadi pengusaha beszar disegani banyak orang dengan berjualan terigu!'Om Liem balas berseru (Npb, 2012:97-80).

Berdasarkan kutipan tersebut jelas Om Liem meyakinkan Papa Edward karena Om Liem sudah memikirkan resikonya dan yakin bahwa bisnis arisan itu dapat mengubah hidup keluarga, dapat terlihat pula kutipan tersebut yang dikatakan Om Liem tidak akan menghabiskan hidupnya dengan berdagang tepung terigu saja.

\section{Ruang Lingkup Makro}

Ruang lingkup makro dalam arti luas ini terdapat pada novel Negeri Para Bedebah dan Negeri Di Ujung Tanduk. Ruang lingkup tersebut merupakan hegemoni yang dilakukan oleh tokoh yang bukan dari anggota keluarga seperti pihak kepolisian, kejaksaan, dan petinggi partai maupun orang suruhan. Berikut penjabarfan hegemoni dalam arti luas yang dialami oleh tokoh di lingkungan sosial.

Berikut kutipan hegemoni Wusdi kepada Thomas.

"Nah, karena anak buahmu sepertinya tidak bias lagi mengemudikan kapal," Wusdi menunjuk Kadek," dan sepertinya kau satu-satunya yang bias, kau sekarang yang mengemudikan kapal. Kita berlayar ke Hongkong. Aku tahu kalian mendaftarkan semua asset itu di sana. Kau akan membawa kami kesana Thomas, membantu memindahkan seluruh aset tersebut, lantas sebagai ucapan terima kasih, berharaplah aku tidak membunuh kau dan орати."

Wusdi kasar mendorong badanku dengan ujung sepatunya.

Aku masih bergeming, berdiri kaku.

"Ayo, Thomas, waktu kita tidak banyak. Atau kau mau aku menembak Opa lebih dulu agar kau melakukannya?(Npb, 2012:420)”

Berdasarkan kutipan tersebut Wusdi meminta Thomas membawanya ke Hongkong.AlasanWusdi menyuruh 
Thomas untuk membantu memindahkan seluruh asset yang dimiliki keluarga Thomas. Wusdi pun sengaja melukai Kadek agar tidak mampu lagi mengemudikan kapal itu sehingga Thomas yang mengantikan posisi Kadek. Disisi lain, Wusdi juga berlaku kasar kepada Thomas dan mengatakan akan menembak Opa jika Thomas tidak ingin melakukanya.

\section{SIMPULAN DAN SARAN}

Berdasarkan penelitian terhadap analisis hegemoni dalam dwilogi novel Negeri Para Bedebah karya Tere Liye (perspektif Antonio Gramsci), dapat disimpulkan bahwa:

Jenis hegemoni dalam penelitian ini mencakup hegemoni fisik dan psikis. (a) Hegemoni fisik yang meliputi Polisi kepada Thomas, Wusdi kepada Thomas, Pasukan Antiteror Hongkong SAR kepada Opa, Thomas, dan Maryam sedangkan (b) Hegemoni psikis yang meliputi tokoh Bintang Tiga Polisi kepada Thomas, Opa kepada Thomas, Julia kepada Thomas, Thomas kepada Maggie, Thomas kepada Julia, dan Ram kepada Opa.

Teknik hegemoni dalam penelitian ini adalah penindasan, intelektual dan moral serta konsensus. Teknik penindasan yang digunakan tokoh Tuan Shinpei untuk menguasi semua harta milik keluarga Thomas dan menjatuhkan JD pada konvensi pemilihan presiden. Teknik penindasan yang dilakukan Tuan Shinpei melalui kaki tangannya yang bernama Ram dan dua orang penting di dalam negeri seperti Wusdi, letnan satu dan Tunga, pejabat muda kejaksaan. Selain itu, Wusdi dan Tunga juga bekerja sama dengan orang suruhan, polisi lokal dan polisi Hongkong. Teknik hegemoni secara intelektual dan moral terbagi menjadi 3 yaitu (1) intelektual tradisional mencakup (a) Thomas kepada Maggie, dan (b) JD kepada Thomas, (2) intelektual organic mencakup (a) Maryam kepada Thomas, (b) detektif Liu kepada Thomas, (c) Thomas kepada JD dan (3) konsensus mencakup (a) Thomas kepada Lee, (b) Maryam kepada Thomas, (c) Thomas kepada Komandan Sipir, dan (d) Thomas kepada Nasbah. Konsensus yang digunakan dalam novel Negeri Para Bedebah dan Negeri Di Ujung Tanduk terjadi antara tokoh Thomas kepada Lee, Maryam kepada Thomas, Thomas kepada Komandan Sipir, dan Thomas kepada Nasabah. Hal ini dilakukan untuk memenuhi apa saja yang dikehendaki oleh tokoh yang menghegemoni dan tentunya adanya persetujuan.

Ruang lingkup hegemoni dalam penelitian ini adalah ruang lingkup mikro dan makro. Ruang lingkup hegemoni mikro terjadi pada anggota keluarga Thomas seperti hegemoni yang dilakukan Om Liem kepada Papa Edward dan Mama kepada Thomas. Selain itu, hegemoni yang dilakukan tokoh tersebut terjadi dalam aspek ekonomi..Ruang lingkup hegemoni makro terjadi pada lingkungan sosial seperti tokoh Wusdi kepada Thomas, Ram kepada Tunga dan Wusdi.Hegemoni yang dilakukan tokoh tersebut terjadi dalam aspek ekonomi dan hegemoni yang dilakukan tokoh JD kepada Thomas terjadi dalam aspek politik.

\section{DAFTAR PUSTAKA}

Faruk.2014. Pengantar Sosiologi Sastra dari Strukturalisme Genetik sampai Post-modernisme. Yogyakarta: Pustaka Belajar.

Gramsci, Antonio. 2013. Prison

Notebooks: Catatan-catatan dari penjara. Yogyakarta: Pustaka Pelajar

Liye, Tere. 2012. Negeri Para Bedebah. Jakarta: Gramedia Pustaka Utama. 
Liyee, Tere. 2013. Negeri Di Ujung Tanduk.Jakarta: Gramedia Pustaka Utama.

Patria dan Arief.2009. Antonio Gramsci, Negara dan Hegemoni.Yogyakarta: Pustaka Pelajar

Ratna, Nyoman Kutha. 2011. Teori, Metode, dan Teknik Penelitian Satra. Jogjakarta: Pustaka Pelajar
Simon, Roger. 2004. Gagasan-Gagasan Politik Gramsci. Yogyakarta: Pustaka Pelajar

Sugiono, Muhadi. 2006. Kritik Antonio Gramsci terhadap pembangunan dunia ketiga.(diterjemahkan oleh Cholish). Yogyakarta: Pustaka Pelajar. Teori, dan Aplikasinya).Yogyakarta: Pustaka Widayautama. 